Dr. Stejneger has called my attention to the fact that the specific name under which $\mathrm{Mr}$. Doolittle's specimen was reported should properly have been written Ambystoma maculatum instead of Ambystoma punctatum, as shown by him in $1902 .^{6}$

\section{GEORGE WASHINGTON UNIVERSITY}

\section{CENTIGRADE VERSUS FAHRENHEIT}

IN the article by A. H. Sabin, appearing in the May 5 issue of ScIEnce, entitled "The Centigrade Thermometer," were expressed the sentiments of many scientific workers, who have had no other method of voicing their opposition to his scheme accorded to them by Representative Johnson, than through articles in various publications.

In the judgment of the writer the set of questions submitted to him by Mr. Johnson should have been so constituted as to have permitted the views of the opposition to have been presented.

The inconvenience of the Fahrenheit scale is not apparent to the writer.

The number denoting the temperature range between the freezing point $\left(32^{\circ}\right)$ and the boiling point $\left(212^{\circ}\right)$ of water, being 180 is divisible without a remainder by $1,2,3,4,5,6,9$ and 10 ; while the number for the Centigrade scale denoting the same range, namely 100 , is divisible by only $1,2,4,5$ and 10 without a remainder; or three less divisors, tending to arouse the suspicion that the Fahrenheit scale is more "rational" than the Centigrade scale.

It is the opinion of the writer that such a change as is contemplated by Mr. Johnson would not only be idiotic, but a most undesirable blow at educational efficiency, the most important factor entering into the life of every human individual.

\section{F. E. Austin}

HANOVER, N. H.

\section{SAFETY RAZOR BLADES FOR HAND} SECTIONING

If there are still any botanists so old-fashioned as to cut sections by hand, they may be

- Proc. Biol. Soc. Wash., Vol. 15, pp. 239-240, December 16, 1902. glad to know, both for themselves and for their students, of the convenience and cheapness of the razor I am now using.

The present stropping handle of the Gem Safety Razor is the holder, the Gem Damascene the blade. The total cost is about fifteen cents. The blades, when dull, can be replaced for five cents, but in the stropping holder they may very easily be kept sharp.

I find this thin, keen, easily stropped razor admirably suited to light work. I am not sure that it would be heavy enough to cut hard wood satisfactorily, but it sections leaves, stems and roots, even of considerable size and hardness. I am so pleased with the result that I wish to share it.

George J. Peirce

\section{Botanical Laboratory, STANFORD UNIVERSITY, CALIFORNIA}

\section{SCIENTIFIC BOOKS}

Ptolemy's Catalogue of Stars. A Revision of the Almagest. By C. H. F. Peters and E. B. KNoBel. Carnegie Institution of Washington, 1915.

It will give pleasure to astronomers to have this long and careful work on the collation of existing manuscript copies of the "Almagest" so well presented in published form. It is the oldest known catalogue of measured star places, and while observers of this day can receive little assistance in comparing those rough measurements with modern positions, the catalogue will still exhibit the changes in the heavens due to precession, and it serves as a record of the unchanging character of the distribution of the bright stars.

No original copy of Ptolemy's "Almagest" is in existence, so far as known, and the earliest manuscripts thus far found were made eight or nine centuries after the epoch of the catalogue. Both Greek and Arabic manuscripts are among the early transcripts; the Latin copies were translations of either one of these. In the transcriptions many errors were made, due in part to the ignorance of astronomical science on the part of copyists, and to the difficulties of translating the nu- 